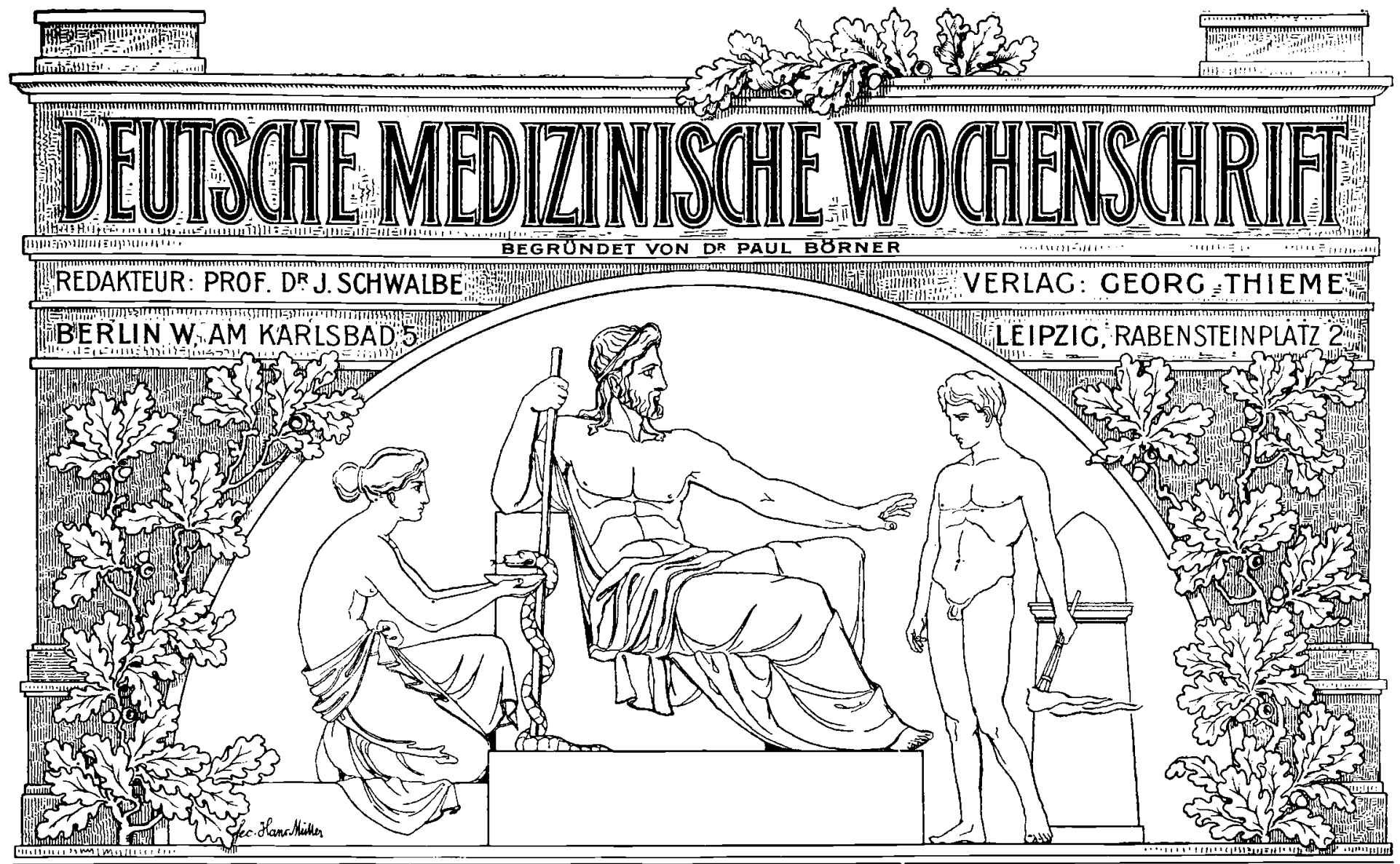

No. 48.

Donnerstag, den 30. November 1905.

31. Jahrgang.

\section{Die Schutzimpfung gegen die Maul- und Klauenseuche.}

Referat erstattet auf dem VII. Internationalen Tierärztlichen Kongresse in Budapest, am 8. September 1905. Von F. Loeffler.

Die enormen Verluste, welche die Maul- und Klauenseuche im Gefolge hat - im deutschen Reiche beliefen sie sich am Ende des vergangenen Jahrhunderts auf über 100 Millionen Mark im Jahre - haben naturgemäß dazu gedrängt, wirksame Maßnahmen zur Bekämpfung der gefürchteten Seurhe zu ermitteln. Die außerordentlich leichte Uebertragbarkeit des Ansteckungsstoffes, namentlich auf die für ihn hochempfänglichen Rinder, in erster Linie durch die Exkrete kranker Rinder, dann aber auch durch Zwischenträger aller Art, durch Menschen und Materialien, welche mit erkrankten Tieren in Berührung gekommen sind, hat in neuerer Zeit dazu geführt, sogar das heroische, bei der Bekämpfung der Lungenseuche und der Rinderpest vielfach bewährte Mittel der Tötung der kranken und ansteckungsverdächtigen Tiere ganz energisch zur Anwendung zu bringen, unbeschadet natürlich der unter Aufgebot zahlreicher Polizeiorgane auf das schär.fste durchgeführten Isolierungs- und Desinfektionsmabregeln und der strengen Ueberwachung und Kontrolle der Sammel-Molkereien, welche als Hauptverbreiter der Seuche erkannt sind. Die Erfolge, welche mit diesen Mannahmen erzielt werden, sollen so befriedigend sein, daß es weiterer Schutzmaßnahmen nicht mehr zu bedurfen scheint. Indessen, wenn auch die genannten Maßnahmen nach Abklingen des letzten, ganz Deutschland beteiligenden groben Seuchenganges genügt zu haben scheinen, um die vereinzelten, hier und da aufflackernden Seuchenausbrüche $\mathrm{zu}$ ersticken, so dürfte doch der Beweis, daß sie wirklich ausreichen, um die Seuche dauernd niederzuhalten, noch nicht als erbracht anzusehen sein, so lange nicht ein so langer Zeitraum verstrichen ist, daß die zahllosen, durch das Ueberstehen der Seuche immun gewordenen Tierc und deren Abkömmlinge durch frische, hochempfängliche Tiere ersetz sind. Erst dann wird es sich zeigen, ob die genannten Maßnahmen, bzw. deren praktische Handhabung, ausreichen, die Seuche dauernd niederzuhalten. Für die Menschenpocken, welche hinsichtlich der Leichtigkeit ihrer Uebertragung sehr wohl mit der Maul- und Klauenseuche in Parallele gestellt werden können, haben die entsprechenden Maßregeln nicht ausgereicht, um sie zu unterdrücken. Erst in Verbindung mit der obligatorischen, allgemeinen Schutzimpfung haben jene Absperr- und Isolierungsmaßnahmen sich als wirklich wirksam erwiesen

Es dürfte deshalb auch gegenüber der Maul- und Klauenseuche ein wirksames Schutzimpfungsverfahren von nicht zu unterschätzendem Werte sein.

Unter welchen Umständen, müssen wir uns fragen, könnte denn nun überhaupt eine Schutzimpfung in Frage kommen? Bricht auf einem Gehöfte die Seuche aus, so wäre es gewiß für den Besitzer in der überwiegenden Mehrzahl der Fülle, namentlich bei der Erkrankung von Milchkühen, von größter Wichtigkeit, wenn die mit den erkrankten Tieren in demselben Stalle stehenden Tiere vor der Erkrankung geschützt werden könnten. Sehr zufrieden würde er sein, wenn die Seuche nur auf den einen Stall, in welchem die Erkrankung aufgetreten, sich beschränken ließe. Auch die an ein verseuchtes Gehöft angrenzenden Besitzer würden gewiß gern ihre Viehbestände einer Schutzimpfung unterziehen, wenn sie durch eine solche vor der Einschleppung der Seuche bewahrt werden könnten. Endlich käme noch der Fall in Frage, daß ein Besitzer frisches Vieh von außerhalb in seine gesunden Bestände importiert. Es würde ihm gewiß von größtem Werte sein, wenn er die mit der Importierung fremder Tiere erfahrungsgemäß oft verbundene Gefahr einer Einschleppung ausschließen könnte.

Die Intensität und die Gefahr der Infektion ist in den vier genannten Fällen nicht die gleiche. Sie ist natürlich am größten in dem Falle, in welchem die gesunden Tiere in demselben Stalle, womöglich neben den erkrankten Tieren stehen; etwas geringer ist sie für Tiere, die auf dem gleichen Gehöfte, aber in andern Stallungen sich befinden, sehr viel geringer in den Fällen sub 3 und 4. Die Menge des Infektionsstoffes, welche in jedem Falle die Infektion bewirkt, spielt eine nicht zu unterschätzende Rolle. Die erkrankten Tiere liefern in den Blasen im Maul, auf der Zunge, an den Klauen und an den Eutern grobe Mengen wirksamer Lymphe, welche beim Platzen in die Luft versprüht, auf das Futter oder in die Wasserrinne 
oder an die Hände und Kleider des Stallpersonals gelangen und von dort aus in den Respirations-, bzw. Digestionstractus der in demselben Stalle stehenden gesunden Tiere übertragen werden können. Tiere, welche in andern Stallungen stehen, können nur durch Zwischenträger, z. B. durch Personen, welche mit den kranken Tieren zu tun hatten, infiziert werden. In diesem Falle handelt es sich in der Regel um viel geringere Mengen von Ansteckungsstoff; und noch geringer sind die Mengen, durch welche meist die Infizierung benachbarter Gehöfte bewirkt wird. Auch bei dem Einstellen fremder Tiere kann es sich nur um Uebertragung geringer Mengen von Ansteckungsstoff handeln. Lenn niemand wird doch Tiere einstellen, welche etwa noch Krankheitserscheinungen oder von nicht ganz abgeheilten Blasen herrührende wunde Stellen im Maule haben. In den Fällen, in welchen eine Infektion durch von auswärts eingeführtes gesundes Vieh bewirkt ist, hat es sich stets um Tiere gehandelt, die zur Zeit der Einführung ganz gesund waren, aber vor kürzerer oder vor längerer Zeit die Seuche überstanden hattell. Es kann sich also in diesen Fällen nur um geringe Mengen von $\mathrm{Er}$ regern handeln, welche an den Klauen in ilgend welchen Rezessen haften geblieben sind oder auch im Maule bei vollkommenem Wohlbefinden des Tieres weiter persistiert haben, wie wir ja z. B. von den Diphtheriebacillen wissen, daß sie im Rachen oder in der Nase erkrankt gewesener Individuen unter Umständen monatelang nach Ablauf der Erkrankung persistieren können. Die Mlenge der die Infektion auslösenden Erreger ist in diesen Fällen stets eine sehr geringe.

Die Anforderungen, welche an ein Schutzimpfungsverfahren gestellt werden, sind in den viel genannten Fällen nicht ganz gleiche. Es wird natürlich leichter sein. ein Tier gegen eine Infektion mit einer winzigen Menge von Infeltions stoff zu schützen als gegen eine Infektion mit großen Dosen desselben. Die Anforderungen werden daher in dem ersten und zweiten Falle größer, in den anderen Fällen geringer sein

Die Möglichleit einer Schutzinpfung beruht auf der durch die Erfahrung gewonnenen und durch das Experiment bestätigten Tatsache, daß das einmalige Ueberstehen der Krankheit einen in der Regel mehrere Jahre währenden Schutz gegen Neuansteckung verleiht. Die Maul- und Klauenseuche verhält sich demnach in dieser Beziehung ähnlich wie die Pockenkrankheit.

Welche Bedingungen mub denn nun ein Schutz impfungsverfahren erfüllen, wenn es in der Praxis verwendbar sein soll?

Erstens muß es ungefährlich sein für die geimpften Tiere zweitens muf es einen wirksamen Schutz verleihen, und zwar für eine gewisse Zeit; drittens muß es leicht ausführbar sein, und viertens muß es möglichst wenig Unkosten machen also billig sein. Nachdem die Tatsache, daß Tiere durch das Ueberstehen der Krankheit Immunität erwerben, gegen jeden Zweifel sichergestellt und nachdem weiterhin experimentell ermittelt war, daß das Blut eines solchen Tieres Stoffe enthält, welche nach Vermischung mit dem in der Blasenlymphe enthaltenen krankmachenden Agens dieses unwirksam zu machen imstande sind, lag es nahe, den Versuch zu machen, das Blut, bzw. Blutserum durchseuchter Tiere zu Schutzimpfungszwecken $\mathrm{zu}$ verwenden. Bei der experimentellen Prüfung des Wirkungswertes dieses Immunblutes zeigte es sich aber bald, daß die. Menge der darin enthaltenen wirksamen Stoffe eine relativ sehr geringe war, sodaß selbst mit großen Mengen, Hunderten von Kubikcentimetern, solchen Blutes ein wirksamer Schutz nicht erzielt werden konnte.

$\mathrm{Da}$ es nun gelungen war, bei einer ganzen Reihe bakterieller Infektionskrankheiten die wirksamen Schutzstoffe im Blute von Tieren durch Einspritzung steigender Mengen der wirksamen Bakterien, bzw. Bakteriengifte in ihrer Menge stark zu erhöhen und so weit.höhere Konzentrationen zu erzielen, als sie im Blute eines Individuums, das die betreffende Krankheit überwunden hat, anzutreffen sind, so schien es auch bei der Maul- und Klauenseuche aussichtsvoll, entsprechende Versuche anzustellen, d. h. Tiere mit steigenden Mengen des Ansteckungsstoffes zu behandeln, um eine stärkere Anhäufung der Schutzkörper in ihrem Blute zu erzielen. Es stellten sich indessen dieser Absicht besondere Schwierigkeiten entgegen, welche vornehmlich darin beruhten, daß die Erreger nicht bekannt waren und nicht rein kultiviert noch in beliebigen Mengen künstlich erzeugt werden konnten. Man war mithin auf die von kranken Tieren $\mathrm{zu}$ gewinnende Lymphe angewiesen. Die Menge der von einem kranken Rinde zu gewinnenden Lymphe war bei der großen Labilität der frisch entstandenen Blasen meist nur eine sehr geringe. Es bedurfte deshalb zahlreicher kranker Tiere, um ein gewisses Quantum Lymphe zu erhalten. Diese Lymphe war nun felner keineswegs eine Flüssigkeit, welche nur die Erregel der Maul- und Klauenseuche enthielt. Bei dem Sitze der Blasen an den Klauen und im Maule war es durchaus selbstverständlich, dab durch den Akt der Gewinnung die Lymphe mit allen möglichen Schmutzteilchen verunreinigt wurde und schließlich eine an allen möglichen Nikroorganismen überreiche Flüssigkeit darstellte, von der man Bedenken tragen mußte, größere Mengen, sei es subcutan, sei es intravenös, Tieren einzuspritzen. Eirst nachdem expcrimentell ermittelt war. daß man die Lymphe nach vorherigem Verdünnen mit Wasser durch BerkefeldFilter filtrieren und dadurch von den flemdartigen Beimengungen zu befreien vermag, ohne ihre spezifische Wirksamkeit zu schädigen, und erst als im Ferkel ein geeignetes Tier zur Fortzüchtung der Lymphe und im Schweine das geeignete Tier für die Gewinnung größerer Lymphemengen erkannt war, konnten die beabsichtigten Versuche in Angriff genommen werden. Es gelang nun, zunächst von Pferden, mithin von Tieren, welche spontan an Maul- und Klauenseuche nicht erkranken, durch Einspritzung steigender Lymphmengen von $1,2,4,8,16,32,64$ ja $100 \mathrm{ccm}$ Lymphe ein Serum zu gewinnen. welches eine ganz außerordentlich viel bessere Schutzwirkung entfaltete als das Blut von Rindern. welche die Krankheit überstanden hatten. Als Prüfungstier bewährte sich in ausgezeichneter Weise das Ferkel. An diesem konnte der Wirkungswert der Lymphe und weiterhin dann auch der der gewonnenen Sera experimentell genau ermittelt werden. Es zeigte sich, daß eine Menge von $0,2-0,3 \mathrm{ccm}$ Serum pro Kilo Ferkel genügte, um diese Tiere vor einer Infektion mit einer tödlichen Dosis Lymphe und ebenso auch vor der spontanen Infektion bein Zusammenleben mit frischkranken Tieren zu schützen. Eine Menge von $5-20 \mathrm{ccm}$ des Serums, je nach der Größe und Schwere der Tiere, zeigte sich in zahlreichen praktischen Versuchen als ausreichend. um Schweine und Schafe selbst inmitten kranker Tiere vor der Infektion sicher zu schützen. Der durch das Serum gewährte Schutz erstreckte sich über drei bis vier, ja selbst sechs Wochen, d. h. über einen Zeitraum, innerhalb dessen die Seuche stets erlischt.

Für Schweine und Schafe ist das Problem der Schutzimpfung mit der Herstellung des hochwertigen Pferdeserums als endgültig gelöst zu erachten.

Anders aber liegt die Sache bei den Rindern. Die mit dem gleichen Serum an Rindern angestellten Versuche ergaben, daß die entsprechenden Mengen von $0,3,0,4$ oder sogar $0,5 \mathrm{ccm}$ pro Kílo wohl auch einen gewissen Schutz gegen die natürliche Ansteckung, wie auch gegen die künstliche Infektion gewährten, daß aber dieser Schutz nur ein relativ kurzdau. ernder, häufig nur 10 bis 14 Tage währender war. Das artfremde Pferdeserum wird schnell ausgeschieden und damit, wie es scheint, auch der darin enthaltene Schutzstoff. Da artgleiches Serum, einem Tiere eingespritzt, länger in dessen Körper verbleibt als artfremdes, so wurde nunmehr versucht, Rinder in ähnlicher Weise wie die Pferde mit steigenden Lymphemengen vorzubehandeln. Die an dieses Serum geknüpften Erwartungen haben sich nun auch erfüllt. Es gelingt mit Mengen von $0,2-0,4 \mathrm{ccm}$ pro Kilo, Rinder für einen Zeitraum von drei bis vier, bisweilen sogar sechs Wochen gegen die Infektion zu schützen. Es hat nur einen Fehler es ist zu teuer. Es ist kaum möglich, das Liter Serum unter 100 Mark herzustellen. Werden dann auch nur $100 \mathrm{com}$ pro Tier gebraucht, so kostet die Schutzimpfung mindestens zehn Mark, ein Preis, welcher von den Tierbesitzern, zumal im Hinblick auf die relativ kurze Dauer des Schutzes, in Norddeutschland wenigstens, hierfür nicht gezahlt wird. In den 
südlicheren Gegenden, in welchen die Maul- und Klauenseuche häufig eine hohe Sterblichkeit der befallenen Tiere im Gefolge hat, dürften die Besitzer indessen gerne einen solchen Betrag zahlen, um die drohenden Tierverluste abzuwenden. In Norddeutschland sterben höchstens junge Saugkälber an der Seuche, fast niemals aber ältere Rinder. Die Schädigungen werden bedingt durch Milchverlust, Verlust an Fleischgewicht bei Masttieren, an Arbeitskraft bei Arbeitstieren, ferner durch Störungen in der Nachzucht. Bei dieser Sachlage entschlieBt sich ein Besitzer nur sehr schwer, eine Summe von zehn oder gar 20 Mark für die Schutzimpfung eines Tieres zu verausgaben. Die Schutzimpfung der Rinder mittels eines hochwirksamen Rinderserums ist daher im wesentlichen eine Kostenfrage. Fül die Praxis komint es darauf an, ein mögligst billiges Verfahren aufzufinden.

Eingehende Versuche haben nun gezeigt, dab man durch oine besondere Anwendungsweise des Serums, durch Inehrmalige Einspritzung mittlerer Dosen von 10 bis $20 \mathrm{ccm}$ in acht- bis zehntägigen Zwischenräumen, sehr gute Schutzeffekte erzielen kann, weit bessere, als durch einmalige Einspritzung einer großen Dosis. In Stallungen, in welchen sich andauernd frischkranke Tiere befanden, konnten Rinder, wofern sie nicht direkt neben die klanken gestellt, also nicht gerade der schwersten Infektion mit großen I.ymphemengen ausgesetzt wurden, monatelang vor der Infektion bewalırt werden. Es jst freilich etwas unständlich, alle acht bis zehn Tage die Einspritzungen wiederholen zu müssen, aber dafür hat man den großen Vorteil, dab der Verbrauch an Serum ein reringerer und daß die Dauer des Schutzes eine sehr viel längere ist als bei einmaliger Einspritzung einer großen SerumInenge. Die vier- bis fünfmal mit diesen mittleren Seruminengen behandelten Rinder haben sich in einer ganzen Reihe von Fällen viele Monate immun gezeigt, sodaß man annehmen muß, daß die so behandelten Rinder eine aktive Immunität durch die wiederholten Serumeinspritzungen erworben haben.

Wiewohl nun diese Art der passiven Immunisierung absolut gefahrlos ist und einen sofortigen, monatelang dauernden Schutz verleiht, so stellen sich doch die noch relativ hohen Kosten, welche sie erheischt, ihrer ausgedehnten, praktischen Anwendung hindernd entgegen. Es muBte inithin noch weiter das Bestreben darauf gerichtet sein, ein noch billigeres Schutzimpfungsverfahren zu ermitteln. Ein solches läßt sich, solange nicht eine künstliche Kultivierung der Erreger und damit eine billige Serumgewinnung möglich ist, nur basieren auf die Verwendung der die Erreger enthaltenden Lymphe. Es handelt sich mithin darum, ein Verfahren der sogenannten aktiven Immunisierung zu finden, weiches den praktischen Anforderungen entspricht.

Eine aktive Immunisierung kann gegenüber den verschiedenartigsten Krankheitserregern in der verschiedensten Weise erzielt werden, entweder durch Einspritzung der Stoffwechselprodukte der Erreger, oder durch Einspritzung der in der Leibessubstanz der abgetöteten Erreger enthaltenen Substanzen, vor allem aber durch Einspritzung der auf irgend eine Weise ihrer Virulenz beraubten, abgeschwächten lebenden Erreger. Die in einer gewissen Menge einem empfänglichen Individuum eingespritzten Substanzen rufen bei diesen eine Reaktion hervor, welche zur Bildung gewisser Antikörper führt und eine Immunität im Gefolge hat analog der, welche durch das Ueberstehen der Krankheit selbst von dem betreffenden Individuum erworben wäre. Die besten Erfolge werden naturgemäß erwartet werden können von einer Einspritzung der lebenden, aber genügend abgeschwächten Erreger selbst. Freilich birgt dieses Verfahren die Gefahr in sich, dab gelegentlich einmal die Abschwächung eine nicht genügend gtarke gewesen ist. In diesem Falle werden die geimpften Individuen erkranken. Handelt es sich um eine Krankheit, bei welcher die befallenen Individuen in der Regel zugrunde gehen, so wird eine durch die Schutzimpfung etwa bedingte leichte oder auch schwerere Erkrankung gern mit in den Kauf genommen, wofern nur dadurch der tö̉diche Ausgang verhütet wird Bei der Maul- und Klauenseuche wäre ein Verfahren, welches eine, wenn auch nur leichte $\mathrm{Er}$ krankung im Gefolge hätte, absolut unbrauchbar, weil die er- krankten Tiere, wenigstens bei uns, nicht sterben und weil die Verluste eben durch das Erkranken der Tiere, wie bereits betont, bedingt werden. Grundbedingung für eine aktive Immunisierung gegen Maul- und Klauenseuche ist also, dab die schutzgeimpften Tiere keinesfalls infolge del' lmpfung erk'anken.

Im Laufe der Jahre, während welcher ich mit den Forschungen über die Maul- und Klauenseuche von der Königlich Preufischen Regierung betraut gewesen bin; sind von mir und meinen Mitarbeitern zahlreiche Versuche unternommen worden, um ein praktisch verwendbares Verfahren zur aktiven Immunisierung gegen Maul- und Klauenseuche aufzufinden. Es handelte sich zunächst daruın, ein Verfahren zu ermitteln, virulente Lymphe so weit abzuschwächen, daß sie nicht mehr krankmachend wirkte. Die Beobachtung, daß verdünnte und dann durch Belkefeldfilter bakterienfrei filtrierte Lympho bei der Aufbewahrung im Eisschrank nach kürzerer oder längerer Zeit ihre Virulenz einbüßt, sodaß selbst größere Mengen davon, $1 / 20$ bis $1 / 10 \mathrm{~cm}$, ein empfängliches Tier nicht mehl krank zu machen vermögen, führte dazu, diese durch Aufbewahren im Eisschlank ihrer klankmachenden Eigenschaften beraubte Lymphe auf etwaige immunisierende Wirkungen zu prüfen.

Die Versuche, welche sowohl an Rindern als auch an Ferkeln angestellt wurden, führten zu der Konstatierung der Tatsache, dab einer solchen Lymphe ohne jeden Zweifel immunisierende Eigenschaften zukommen. Die an vielen Dutzenden von Ferkeln angestellten Versuche haben ergeben, daß durch Einspritzung von $1 / 10$ bis $2 / 10 \mathrm{ccm}$ solcher Lymphe die Tiere eine gewisse, häufig sogar eine sehr erhebliche Immunität erwerben, sodab sie, mit kranken Tieren zusammengebracht und gehalten, nicht erkranken. Auch bei Rindern wurden in zahlreichen Versuchen sehr gute Ergebnisse erzielt. Es bestand nur eine Schwierigkeit. Man muß zunächst sich ein größeres Quantum Lymphe verschaffen, was ja nicht so schwierig ist, und muß nun diese Lymphe fortdauernd kontrollieren durch Probeimpfungen von Tieren, bis man den Zeitpunkt ermittelt hat, in welchem eine Menge von $1 / 10$ bis $2 / 10$ ccm Ferkel nicht mehr krank macht. Dann ist die Lymphe zur Schutzimpfung geeignet. Dieser Zeitpunkt wird bei Lymphen, welche von verschiedenen Tieren stammen, nach sehr verschieden langer Zeit erreicht. Lagert nun die Lymphe weiter. so nehmen ihre immunisierenden Eigenschaften ab, bis sie schlieblich gänzlich verschwinden. Dieser Zeitpunkt ist sehr schwer' zu bestimmen. Er kann nur durch immer wiederholte Immunisiel'ungsversuche ermittelt werden. Der Zeitraum, welcher verstreicht von dem Verschwinden der krankmachenden Wirkung bis zum Verschwinden der immunisierenden Kraft ist nun ebenfalls bei Lymphen verschiedener Provenienz verschieden. Man hat also in der durch Lagern im Eisschrank abgeschwächten Lymphe ein Material vor sich, welches in seiner Wirksamkeit sehr schwierig zu beurteilen ist. Dieser Umstand ist die Ursache, weshalb wir von der praktischen Verwendung solcher Lymphe schlieblich definitiv Abstand genommen haben.

Es wurde deshalb versucht, frische virulente $L_{y y m p h e}$ durch Anwendung der Wärme in ein geeignetes Immunisierungsmaterial umzuwandeln. Es zeigte sich, daß durch Erwärmen bis auf 60", durch halbstündiges Erwärmen auf $55^{\circ}$, durch zwölfstündiges Erwärmen auf $37^{\circ}$ die Lymphe abgeschwächt werden kann. Aber ganz gleichmäßige Ergebnisse ließen sich auch auf diesem Wege nicht erzielen. Verschiedene Lymphen zeigten sich rerschieden widerstandsfähig gegenüber den genannten Behandlungsverfahren. Ein praktisch brauchbares Verfahren konnte nicht erzielt werden. Auch Zusätze von solchen chemischen Stoffen, welche erfalırungsgemä $B$ in gewissen Konzentrationen zur Abschwächung geeignet sind, führten nicht zur Herstellung eines verwendbaren Immunisierungsmaterials.

Da der zur Schutzpockenimpfung gegen die Menschenpocken verwendete Impfstoff, die Kuhpockenlymphe, erwiesenermaßen nichts anderes ist als das durch die Fortzüchtung im Körper des Rindes in seinen Qualitäten veränderte, insbesondere für den menschlichen Organismus abgeschwächte Virus der Menschenpocken, so erschien es aussichtsvoll, zu versuchen, das von Rindern gewonnene Maul- und Klauenseuchevirus dauernd im Körper einer andern, weniger für dasselbe empfänglichen Tierart, im Schweine fortzuzüchten, um zu sehen, ob durch andauernde Züchtung in diesem Tier das 
Virus etwa in seiner Virulenz für das Rind abgeschwacht und dann als Schutzimpfungsmaterial für Rinder verwendet werden könnte.

Wie früher mitgeteilt, schwächt sich das Maul- und Klauenseuchevirus durch Fortzüchtung im Schweine, bzw. im Rinde derart $a b$, daß bereits nach drei bis vier Uebertragungen die Weiterzüchtung nicht mehr gelingt und die Reihe abreißt. Es war deshalb notwendig, bei der Fortzüchtung abwechselnd Rinder und Schweine zu infizieren. Später wurde dann ermittelt, daß das junge Schwein, das Ferkel, viel empfänglicher ist als das erwachsene Schwein und daß es möglich ist, die Lymphe im Ferkelkörper danernd fortzuzüchten. A uf diese Weise wurde ein Lymphestamm seit nunmehr fast sechs Jahren erhalten. Nur in größeren Zwischenräumen wurde die Lymphe durch ein Rind geschickt. Von einem bestimmten Zeitpunkte an wurde der Lymphestamm auf zweierlei Weise weiter gezüchtet, der eine Zweig ausschließlich im Ferkel, der andere abwechselnd im Rind und im Ferkel. Es zeigte sich nun, daß der ausschließlich im Ferkel gezüchtete Zweig an Virulenz abnahm. - Häufig blieben die Ferkel nach Einspritzung der gewöhnlichen Dosis Lymphe $1 / 60 \mathrm{ccm}$ gesund, so daß größere Dosen $1 / 20,1 / 10$ ja selbst $2 / 10 \mathrm{ccm}$ eingespritzt werden mußten, während der abwechselnd durch Rinder und Ferkel gezüchtete Stamm seine alte Virulenz bewahrte.

Das Abschwächungsphänomen trat deutlich auch bei Rinderimpfungen hervor. Auch die Rinder erkrankten mehrfach nach 1/80, ja selbst $1 / 10 \mathrm{ccm}$ Lymphe nicht mehr und erwiesen sich dann gegen die lnfektion mit der virulenten Lymphe des andern Zweiges imnun. Leider aber ging die Abschwächnng nicht gleichmäßig voran. Sie war besonders deutlich und auffallend, als ich längere Zeit Ferkel der gleichen Rasse von demselben Besitzer beziehen konnte. Sobald aber Ferkel anderer Provenienz bzw. anderer Rassen zur Fortzüchtung benutzt werden mußten, weil nicht genügend Ferkel der gleichen Rasse von demselben Besitzer geliefert werden konnten, traten sofort wieder entweder starke Virulenzsteigerungen oder aber solche Abschwächungen ein, daß die Fort züchtung abzureißen drohte. Da es trotz aller Bemühungen nicht möglich war, andauernd Ferkel derselben Rasse und Provenienz für die Fortzüchtung der Lymphe zu beschaffen, so muBte schließlich von den Versuchen, durch Fortzüchtung im Ferkel einen fïr Rinder abgeschwächten Lymphestamm zu gewinnen, Abstand genommen werden.

Die Versuche würden, da sie durchaus nicht ergebnislos waren, wieder aufgenommen worden sein, wenn nicht inzwischen ein anderes Verfahren von mir aufgefunden worden wäre, welches gute Ergebnisse versprach. Wie bereits erwähnt, basiert die Herstellung des Schutzserums auf der Tatsache, daß Rinder, welche die Maul- und Klauenseuche überstanden haben, in ihrem Blute Stoffe enthalten, die die in der Lymphe vorhandenen Krankheitserreger unschädlich zu machen imstande sind. Bei den diesbezüglichen experimentellen Untersilchungen hatte sich nun herausgestellt, dab Rinder, die solche Immunblutlymphegemische eingespritzt erhalten hatten und nach der Einspritzung nicht erkrankt waren, einen erheblichen Grad von Immunität erworben hatten. Es schienen deshalb solche lmmunblutlymphegemische zu Immunisierungszwecken geeignet zu sein.

Um die Wirkung des Immunblutes oder -serums zu verstärke und jede krankmachende Wirkung der in bestimmter Menge zugesetzten Lymphe auszuschließen, wurden damals schon - im Jahre 1898 - die das Serum liefernden immunen Rinder vor der Blutabnahme mit größeren Dosen Lymphe behandelt. Das Präparat wurde von den Höchster Farbwerken unter dem Namen "Seraphthin ${ }^{*}$ in den Handel gebracht. Vielfach wurde die gute immunisierende Wirkung des Seraphthins in der Praxis bestätigt. Indessen nach kurzer Zeit mußte die Abgabe des Präparates sistiert werden, weil in einer Anzahl von Fällen die mit dem Seraphthin behandelten Rinder etwa zwei Wochen nach der Einspritzung an Manl- und Klauenseuche erkrankten. Wie sich ergab, war ein neuer, sehr virulenter Lymphestamm in den Betrieb eingeführt worden, weil der alte, in Ferkeln fortgezüchtete Stamm eine so starke Abschwächung dargeboten hatte, daß mit seiner Hilfe nicht mehr die erforderlichen Mengen von Lymphe hatten gewonnen werden können. Die in der neuen, aus einem frischen Seuchenausbruch beschafften Lymphe enthaltenen Erreger vermochte das damalige Serum wohl für etwa 12-14 Tage im Zaume zu halten, dann aber gewannen die in dieser Zeit noch nicht abgestorbenen Erreger die Oberhand und machten die geimpten Tiere krank.

Nachdem es nun später gelungen war, ein hochwertiges Serum herzustellen und die Lymphe konstant weiter zu züchten, wurden die alten Seraphthinversuche wieder aufgenommen.
Es zeigte sich, dal $10 \mathrm{ccm}$, ja sehon $5 \mathrm{ccm}$ Serum imstande waren $1 / 50$ bis $1 / 20 \mathrm{ccm}$ frischer Lymphe vollständig unschädlich zu machen. Eine solche Einspritzung hatte aber entweder gar keine oder doch nur eine sehr schwache Immunität zur Folge. Es wurden deshalb die Einspritzungen in acht- bis zehntägigen Zwischenräumen zwei- und auch dreimal wiederholt. Die Ergebnisse waren jetzt besser, aber doch noch seh. ungleichmäßig. Vermutlich war die Serumwirkung zu atark, sodab die in der zugesetzten Lymphe enthaltenen Erreger zu schnell vernichtet wurden, bevor sie eine genügende, zur Immunität führende Reaktion auslösen konnten.

Bei den zahlreichen Versuchen, einen geeigneten Prüfungsmodus für das hochwertige Rinderserum zu ermitteln, wurde schließlich als geeignetster Modus befunden die intravenöse Einspritzung von $100 \mathrm{ccm}$ Serum und 24 Stunden später, ebenfalls intravenös, von $1 / 10$ ccm Lymphe. Erkrankten zwei oder auch drei junge Rinder nach dieser Behandlung nicht, so wurde das Serum als für Immunisierungszwecke genügend erachtet. Die Rinder, welche zu den Serumprüfungen verwendet waren, wurden nun drei bis vier Wochen später daraufhin geprüft, ob sie Immunität erworben hatten. Die Prüfung wurde vorgenommen mit verschiedenen Lymphemengen. Bei diesen Versuchen stellte sich heraus, daß die Tiere wohl immun geworden waren, dab aber ihre Immunität keine sehr hohe war. Sie vertrugen stets $1 / 300 \mathrm{ccm}$ Lymphe; nach $1 / 100 \mathrm{ccm}$ erkrankten schon manche Tiere. Weitere Versuche lehrten aber, daß die durch die vorausgegangene Serum- und Lympheeinspritzung erworbene Grundimmunität durch Injektionen von $1 / 300,1 / 100,1 / 25,1 / 10 \mathrm{ccm}$ Lymphe in etwa zehntägigen Zwischenräumen derart gesteigert werden konnte, daß die Tiere beliebige Mengen Lymphe vertrugen und, neben schwerkranke Tiere gestellt, nicht erkrankten.

Nach den Einspritzungen der Gemische von hochwertigem Serum und Lymphe war die etwa entstandene Immunität entweder durch Einstellen zwischen kranke Tiere oder durch Einspritzung von mindestens $1 / 50$, meist $1 /{ }_{25}$ oder $1 / 20 \mathrm{~cm}$ virulenter Lymphe geprüft worden. Die Höhe der Anforderungen dürfte nicht ohne Bedeutung für den ungleichwertigen Ausfall der Ergebnisse geworden sein. Gut reagierende Tiere hatten wohl eine den hohen Ansprüchen genügende Immunität erworben, die weniger gut reagierenden aber nicht. Nach dem Ausfall der Serumprüfungsversuche war es unbedingt notwendig, auch die Prüfungen auf Immunität nach Einspritzung von Serum-Lymphegemischen mit einer kleinen Dosis Lymphe, $1 / 300 \mathrm{ccm}$ zu beginnen, um festzustellen, ob alle Tiere durch solche Einspritzungen eine gewisse Grund-Immunität zu erwerben imstande sind.

Moch ein zweites Moment war auferdem zu beachten. Die Tiere, welche die Seuche überstanden haben, erwerben dadureh Immunität. Diese ist aber erst nach frühestens drei Wochen deutlich nachweisbar. Bei Versuchen, welche ich seinerzeit mit Dr. K uprianow über die immunisierende Wirkung von Diphtheriebacillen und Diphtherieserum angestellt habe, hatte sich herausgestellt, daß nur diejenigen Tiere späterhin der Einspritzung der tötlichen Dosis Diphtherie-Bouillonkultur widerstanden, welche frühestens $31 / 2$ Wochen später probegeimpft wurden. Es schien deshalb geboten, bei den mit Maul- und Klauenseucheserum-Lymphegemischen behandelten Rindern die Prüfung auch erst nach $31 / 2$ Wochen, und zwar mit $1 / 300$ ccm Lymphe vorzunehmen.

Es hatte sich nun weiterhin noch herausgestellt, daß die Injektionen der Serum-Lymphegemische besonders gut vertragen wurden, wenn sie unter die Haut und nicht in die Blutbahn gemacht wurden. Die subcutan behandelten Tiere schienen auch besser immun zu werden als die intravenös behandelten.

Die Versuche, welche mit Serum-Lymphegemischen an gröberen Reihen von Tieren angestellt worden sind, haben zu dem interessanten Ergebnisse geführt, dab außerordentlich geringe Mengen eines hochwertigen Serums genügen, um die krankmachende Wirkung ziemlich grober Lymphemengen, $1 / 20$ ccm bei subcutaner Einspritzung des Gemisches, zu verhindern. Tiere, welche $5,4,3,2,1,0,75,0,5,0,25$ Serum 
erhalten hatten, erkrankten nicht. Erst bei $0,1 \mathrm{ccm}$ Serum, vermischt mit $1 / 20$ Lymphe, erkrankten einzelne Tiere.

Im Hinblick auf diese geradezu überraschende Wirksamkeit des hochwertigen Serums war es von größtem Interesse, zu ermitteln, wie sich denn nun die Immuniät der Rinder nach der Einspritzung so kleiner Serummengen, vermischt mit einer immerhin größeren Dosis Lymphe, gestalten würde. Ich möchte einen unter Berücksichtigung sämtlicher oben hervorgehobener Momente an 10 Rindern angestellten Versuch etwas ausführlicher mitteilen, weil er die Grundlage für ein neues Immuni. sierungsverfahren geliefert hat.

Von 10 jungen, ganz einwandfreien, aus einer in früherer Zeit noch niemals durchseuchten Herde stammenden Rindern hatten er. halten:

3 Rinder $2 \mathrm{ccm}$ Serum und $1 / 2_{0} \mathrm{ccm}$ virnlenter Lymphe,

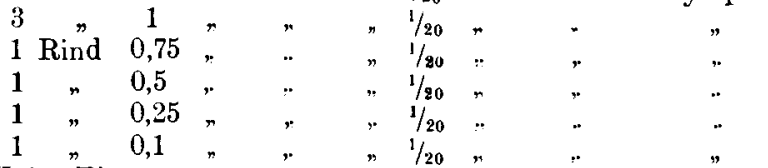

Kein "Tier war" nach" der "Einspritzung erkrankt. Die Tiere hatten zunächst in einem vollständig isolierten Stalle gestanden und waren dann. 18 Tage nach der Einspritzung, in das Seuchengehöft überführt und dort in einen von dem Seuchenstalle getrennten, auf der andern Seite des Hofes in der Scheune gelegenen Stall eingestellt worden. Sie waren voll diesem Zeitpunkte an der natürlichen Infektion ausgesetzt, da sie auf dem Seuchengehöfte von denselben Wärtern gefüttert wurden, welche auch die kranken, im Seuchenstalle stehenden Rinder zu versorgen liatten. Sieben Tage nach der Ueberführung erkrankte ein Tier, welches $2 \mathrm{ccm}$ Serum und $1 / 20$ virulente Lymphe erhalten liatte. Die übrigen blieben gesund.

14 Tage nach der teberfïhrung, 32 'Tage nach der Impfung erhielten:

1 Rind mit $2 \mathrm{ccm}$ Serum und $1 / 20$ Lymphe - 1/soo virulenter Lymphe; es erkrankte leicht nach 7 Tagen.

1 Rind mit $2 \mathrm{ccm}$ Serum und 1/20 Lymple - 1/100 virulenter Lymphe; es erkrankte leicht nach 7 Tagen.

2 Rinder mit $1 \mathrm{ccm}$ Serum und $1 / 20$ Lymphe - 1/300 virulenter Lymphe; das eine erkrankte leicht nach 6 Tagen. das zweite erkrankte nicht.

1 Rind mit $1 \mathrm{ccm}$ Serum und $1 / \mathrm{w}_{0}$ Lymphe - 1/10) virulenter Lymphe; es erkrankte leicht nach 3 Tagen.

1 Rind mit 0,75 ccm Serum und 1/20 Lyinphe - 1/300 virulenter Lymphe; es erkrankte nicht.

1 Rind mit $0,5 \mathrm{ccm}$ Serum und 1/2n Lymphe - 1/100 virulenter Lymphe; es erkrankte nicht.

1 Rind mit 0,25 ccm Serum und 1/20 Lymphe - 1/300 virulenter Lymphe; es erkrankte nicht.

1 Rind mit $0,1 \mathrm{ccm}$ Serum und $1 / 20$ Lymphe - 1/100 virulenter Lymphe; es erkrankte nicht.

Der Versuch hatte mithin das merkwürdige Ergebnis. daß die drei Tiere mit $2 \mathrm{ccm}$ Serum und $1 / 20$ virulenter Lymphe alle drei erkrankt waren, von den drei Tieren mit $1 \mathrm{ccm}$ Serum und $1 / 20$ virulenter Lymphe zwei erkrankten, und von den vier Tieren mit $0,75, \quad 0,5,0,25$ und 0,1 Serum und ${ }_{1 / 20}$ virulenter Lymphe keines erkrankte.

Durch nachfolgende, in etwa 14 tägigen Zwischenräumen vorgenommene Injektionen ron 1/100 und 1/25 ccm Lymphe wurden die Tiere so hoch immun, daß sie, während sechs Wochen zwischen stets frisch kranke Tiere eingestellt, vollkommen gesund blieben.

Dieser Versuch und eine Reihe anderer Versuche führten mithin zu den prinzipiell überaus wichtigen Ergebnissen: 1. dab bei Einspritzungen von SerumLymphegemischen die Serummenge in einem bestimmten Verhältnis zur Lymphe stehen muB, wenn eine gleichmäßige Grund-Immunität erzielt werden soll; 2. daB es möglich ist, diese Grund-Immunität mit Hilfe sehr geringer Serummengen herbeizu. führen; 3 . dab es sicher gelingt, die relativ schwache Grund-Immunität durch nachfolgende Einspritzungen von Lymphe zu einer sehr hochgradigen zu machen.

Die Serummenge und die Lymphmenge müssen derart mit einander austitriert sein, dab die Lymphe zwar an ihrer krankmachenden Wirkung verhindert, aber doch nicht vollkommen unwirksam gemacht wird, d. h. sie darf nur soweit abgeschwächt werden, daß sie noch eine zur Erzeugung der Immunität ausreichende Reaktion im Tierkörper auszulösen ver- mag. Die Menge des einer bestimmten Menge, z. B. $1 / 20 \mathrm{ccm}$ einer bestimmten Lymphe zuzusetzenden Serums kann unbeschadet der immunisierenden Kraft des Gemisches innerhalb bestimmter Grenzen variieren. In den mitgeteilten Versuch lagen die Grenzen des Serumzusatzes zwischen $1 \mathrm{ccm}$ und $0,1 \mathrm{ccm}$. Man wird natürlich nicht gerade die eben noch neutralisierende Serumdosis wählen, sondern, um ganz sicher zu gehen, eine etwas höhere. Die beiden Faktoren. das Serum und die Lymphe, sind an sich nicht ganz konstante Größen. Serum von einem gleichmäßigen Wirkungswerte läßt sich abel unschwer in großen Mengen herstellen. Ein kräftiger Ochse liefert, wenn man ihn aus der Halsschlagader entblutet, etwa zehn Liter Serum. Nimmt man gleichzeitig z. B. fünf Ochsen in Behandlung, so erhält man nach Vermischen der Sera 50 Liter Serum. Würde nun z. B. für ein zu immunisierendes Rind $0,5 \mathrm{ccm}$ Serum benötigt, so würde diese Serummenge fül. 100,000 Rinder ausreichen. Das Serum erhält sich jahrelang wirksam. Der Serumfaktor in dem Serum-Lymphe-Gemisch kann demnach als konstant angesehen werden. Nicht so konstant zu gestalten vermag man den zweitell Faktol, die Lymphe. Ihre Virulenz schwankt etwas. auch bei möglichst gleichmäßigem Fortzüchtungsmodus, je nach der Individualität des die Lymphe liefernden Tieres. Durch Vermischen der voll ver'schiedenen Tieren gewonnenen Lymphen läßt sich aber immelhin ein genügend gleichmäßig wirkendes Material gewinnen.

Von großer Wichtigkeit ist ferner die Frage. welche Menge Lymphe ist in minimo erforderlich, damit eine Immunisierungswirkung erreicht wird? $5 / 1001 \mathrm{ccm}$ reichen sicher dazu aus. wie wir gesehen haben. Weitere Versuche haben gezeigt, dab s(1gal nur. $1 / 100$ ccin schon genügt.

Bei der Prüfung zahlreicher, von den verschiedensten Tieren, Schweinen und Kindern, gewonnenen Lymphen that sich nun ergeben, daf 0,5 ccm Serum stets ausgereicht haben. um $3 / 100 \mathrm{ccm}$ Lymphe sicher unschädlich zu machen und Grundimmunität zll erzeugen sowohl bei jungen wie bei älteren Rindern.

Das neue Immunisierungsverfahren besteht also darin, $\mathrm{da} B$ den zu immunisierenden Rinder 0,5 ccm hochweltigen hinderserums vermisch t mit $3 / 100-0,03 \mathrm{ccm}$ frischel. virulenter Lymphe unter die Haut gespritzt werden. Nach 24 bis 26 Tagen wird ihnen 1/300-0,0033 ccn Ly mphe ebenfalls unter die Haut gespritzt, nach weiteren 1.2 bis 14 Tagell $1 / 100-0,01 \mathrm{ccm}$ Lymphe, nach ferneren 1: bis $1 t$ Tagen $1 / 25-0,04 \mathrm{ccm}$ Lymphe. Nach der zweitell Einspritzung von $1 / 100 \mathrm{ccm}$ Lymphe ist die Immunität beleits eine sehr erhebliche, sodaß sie für die praktischen Verhältnisse ausreicht.

Das Verfahren hat sich auf der Versuchsstation bis jetzt ausgezeichnet bewährt. Einigen zwanzig Rindern ist durcl dasselbe eine Immunität verliehen worden, welche den höchsten Anforderungen entspricht und der durch das Ueberstehen der Krankheit erworbenen gleichkommt.

Vier Rinder, die im Januar und Februar immunisiert worden waren, wurden bis Anfang Mai im Seuchenstalle gehalten, ohne zu erkranken. Dann wurden sie in eine Koppel übergeführt und darin bis zum 19. August belassen. An diesem Tage wurden sie zum zweiten Male in den mit stets frisch kranken Tieren besetzten Seuchenstall eingestellt. Sie sind bis heute gesund geblieben. Die Immunität hält daher länger als ein halbes Jahr an, und vermutlich ist ihre Dauer eine noch sehr viel längere. ${ }^{1}$ )

Das Verfahren ist zwar etwas umständlich, weil zu dessen vollständiger Durchführung vier Einspritzungen erforderlich sind. Aber es ist ungefährlich und vor allem außerordentlich billig. $0,5 \mathrm{ccm}$ Serum kosten bei einem Preise von 100 Mark für das Liter nur fünf Pfennige, und wenn der Preis selbst 200 Mark betrüge, nur zehn Pfennige. Der Kubikzentimer Lymphe läßt sich zum Preise von fünf Mark herstellen. Für drei Injektionen werden gebraucht ${ }^{3 / 100}, 1 / 300$ und $1 / 100 \mathrm{ccm}$ - rund $5 / 100 \mathrm{ccm}$, welche 25 Pfennige kosten würrden, für vier Injektionen wären $5 / 100$ und $4 / 100$ ccm erforderlich, gleich 45 Pfennige. Das gesamte für ein Rind erforderliche

1) Die vier Rinder sind auch jetzt noch gesund. 
Impfmaterial würde mithin 30-50 Pfennige kosten - ein Betrag, gegen dessen Höhe die Tierbesitzer Bedenken wohl nicht erheben würden.

Fassen wir die Ergebnisse der Schutzimpfungsversuche zusammen, so stehen uns für die Schutzimpfungen in der Praxis zur Verfügung folgende Verfahren: 1. Einspritzung hochwertigen Serums von Pferden für Schweine und Schafe in den Mengen von $5-20 \mathrm{ccm}$ je nach dem Gewicht; von Rindern für Rinder; a) einmalige große Dosis von $0,3-0,5 \mathrm{ccm}$ pro Kilo; b) in achttägigen Zwischenräume wiederholte Dosen von 15--20 ccin intravenös; 2. Einspritzung von Serum und Lỳmphegemischen für Rinder: 0,5 hochwertiges Rinderserum vermischt mit $3 / 100$ ccm virulenter Lymphe unter die Haut

nach $3 \frac{1}{2}$ Wochen $1 / 300$ ccm Lymphe unter die Haut;

$\begin{array}{llllllll}12-14 & " & 1 / 10 & & & & & \end{array}$

Es fragt sich nun, welches Verfahren in den verschiedenen oben angeführten Fällen anzuwenden wäre:

1. In Stallungen, in welchen die Seuche ausgebrochen ist, bei Rindern, Schweinen und Schafen: Verfahren 1 a.

2. In Stallungen auf verseuchten Gehöften, in denen noch kein Tier erkrankt ist:

Verfahren $1 \mathrm{~b}$, vielleicht auch Verfahren 2.

3. In gesunden Beständen in der Nachbarschaft verseuchter Gehöfte: Verfahren 2.

Wenn es auf die Kosten nicht ankommt, llamentlich auch in unmittelbarer Nachbarschaft verseuchter Gehöfte und bei regem Verkehr: Verfahren $1 \mathrm{~b}$

4. In gesunden Beständen, in welche Tiere von außerhalb eingeführt wurden: Verfahren $1 \mathrm{~b}$.

Für eine allgemeine Schutzimpfung, bei bedrohlicher Ausbreitung der Seuche würde sich ihrer Billigkeit wegen nur das Verfahren 2 eignen.

Die sogenannten Notimpfungen in Beständen. in welchen die Seuche ausgebrochen, müßten ungeachtet des wirtschaftlichen Vorteils der schnellen Durchseuchung der Bestände, ebenso wie die Schafpockenimpfung, die Ovination, und die Menschenpockenillpfung, die Variolation, verboten werden, weil durch diese, stets eine inehr oder weniger schwer verlaufende Erkrankung bedingende Impfung die Menge des verschleppbaren Infektionsstoffes in einein gegebenen Zeitpunkte ganz außerordentlich vermehrt wird

Dagegen müßte den Besitzern das zur Schutzimpfung erforderliche Material vom Staate unentgeltlich zur Verfügung gestellt werden, weil ja die durch die Schutzimpfung erreichbare Einschränkung der Seuche im allgeıneinen Interesse liegt. Ferner dürften die Schutzimpfungen nur von Sachverständigen, den Tierärzten, ausgeführt werden. Zu wünschen wäre endlich, daß, in analoger Weise wie bei den Schutzimpfungen gegen den Rotlauf der Schweine, den Besitzern für etwaige durch die Impfungen hervorgerufene Schädigungen staatlicherseits eine Entschädigung zugebilligt würde. 